\title{
Marfan Syndrome: When A Consultation for Foot Deformities Results in Cardiac Surgery
}

\author{
Ait Malek S*, El Bouchti I
}

Department of Rheumatology, Mohamed VI university Hospital, Marrakesh, Morocco

\author{
DOI: $10.36348 /$ sjmps.2020.v06i08.011 | Received: 06.08.2020 | Accepted: 13.08.2020 | Published: 30.08 .2020 \\ *Corresponding author: Ait Malek S
}

\section{Abstract}

Marfan syndrome is an inherited autosomal dominant connective tissue disorder known for its multiple pathologies: musculoskeletal, pulmonary, ocular and cardiovascular. The criteria of Ghent facilitate its diagnosis. It requires a complete clinical examination as well as multiple imaging modalities. Early diagnosis and medical treatment with betablocker can delay the progression of aortic dilatation or possibly stop the pathological process of the aortic wall, as well as timely elective surgery are the key measures to improve the outcome of this disease. We report here the fortuitous discovery of a Marfan syndrome in a 19-year-old patient complicated with aortic dilatation.

Keywords: Marfan syndrome, Aortic dilatation, Ghent criteria.

Copyright @ 2020: This is an open-access article distributed under the terms of the Creative Commons Attribution license which permits unrestricted use, distribution, and reproduction in any medium for non-commercial use (NonCommercial, or CC-BY-NC) provided the original author and source are credited.

\section{INTRODUCTION}

Marfan syndrome (MS) is an inherited genetic disease with autosomal dominant transmission affecting connective tissues, particularly cardiovascular, musculoskeletal and ocular. The incidence is estimated at $1 / 5000$ births [1]. However, this pathology remains unknown.

We describe in this article the case of a patient whose admission to the rheumatology department for the management of deformities of the feet leads to the accidental diagnosis of Marfan syndrome.

\section{Case Report}

We report the case of a 19 year old woman with no medical history. Admitted to our department for feet deformities: Hallux valgus bilateral, valgus heel, suppradductus and Toes in claws (figure 1).

The clinical examination at admission found a stable patient with a heart rate of 93 beats per minute, a blood pressure of $126 / 54 \mathrm{mmHg}$.

In addition, the patient was $175 \mathrm{~cm}$ tall and had a pectus carinatum deformity, an arachnodactyly (wrist and thumb sign +) (figure 2) with joint hypermobility (Beighton criteria > 4/9), flat feet and stretch marks (figure 3).
The biological tests showed absence of inflammatory syndrome. Ophthalmological examination revealed a subluxation of the lens in the left temporal axis.

In addition, there was no evidence of cardiac murmur in the auscultation, transthoracic ultrasound showed aortic dilatation of $63 \mathrm{~mm}$ (Valsalva sinus) and $46 \mathrm{~mm}$ (aortic ring) without intimal flap or severe aortic insufficiency or pulmonary arterial hypertension and with preservation of systolic function.

The patient was transferred to the cardiovascular surgery department where a Bentall intervention with the placement of a mechanical valve tube and coronary reimplantation were performed.

\section{DisCUSSION}

Marfan's syndrome is an autosomal dominant connective tissue genetic dystrophy resulting from the mutation of the Fibrillin Type 1 (FBN1) gene [1] on the chromosomal band. The data on the MFS were enriched by the description of a form linked to mutations of TGF $\beta[2]$.

Family history is not always contributive since neomutation is involved in about $25 \%$ of cases with mutations located on the fibrillin gene (FBN1) [2]. 
Fibrillin, a glycoprotein that is part of the structure of the extracellular matrix widely expressed in the body and which explains the diversity of clinical signs found in MS that may be skeletal, ocular, cardiovascular, cutaneous, pulmonary and neurological (Table 1) [3].

Its prevalence is estimated at one in 5000 births taking into account incomplete forms [1], this means that 10,000 to 12,000 people suffer from this syndrome in France.

Its severity is due to cardiac involvement with progressive dilatation of the aorta favoring dissection and rupture that could be avoided by timely cardiovascular surgery, thus reinforcing the need for early diagnosis in MS [4].

The diagnosis of Marfan syndrome is mainly clinical, based on a set of major and minor criteria, related to the different systems involved according to Ghent's nosology [5].
Therapeutics is preventive and relies on patient education, sport limitation, beta-blockers alone, proven to have a proven effect on aortic dilatation, regular echocardiographic monitoring (annual cardiac ultrasound), and replacement surgery. The aortic replacement surgery is indicated when the aortic dilatation exceeds the threshold of $50 \mathrm{~mm}$ [6].

New treatments are currently being tested but have not been proven effective. The overall care of the patient, taking into account the difficulties related to the genetic origin of the disease, the aesthetic and psychological consequences allows an improvement of the quality of life [7].

\section{CONCLUSION}

Marfan syndrome is a genetic disorder still unknown with variable clinical expression and whose prognosis depends on the associated cardiovascular complications. The management requires a multidisciplinary approach is, at best, provided in a reference center.

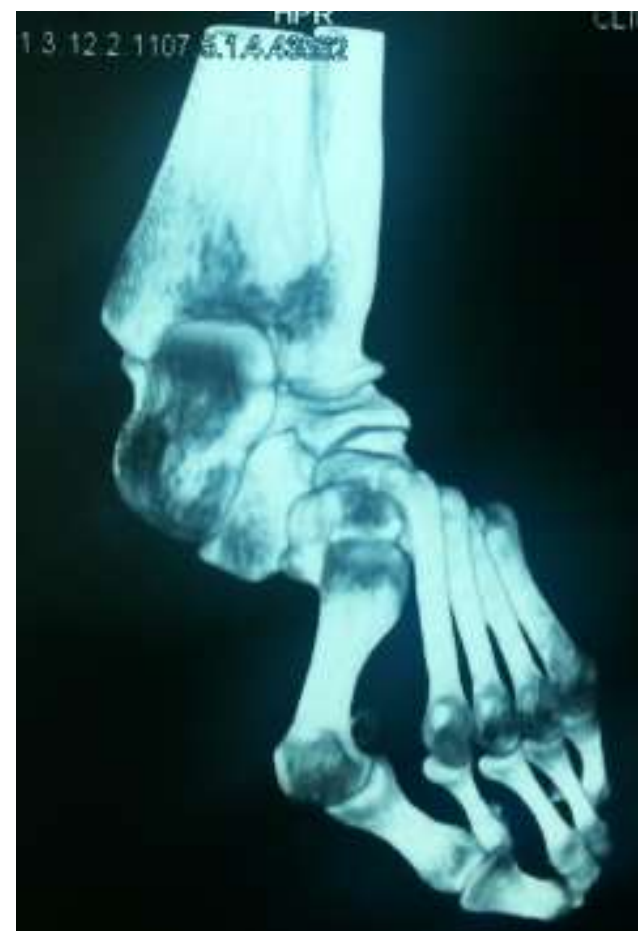

Fig-1: the CT scan image shows feet deformities: Hallux valgus bilateral, valgus heel, suppradductus and Toes in claws

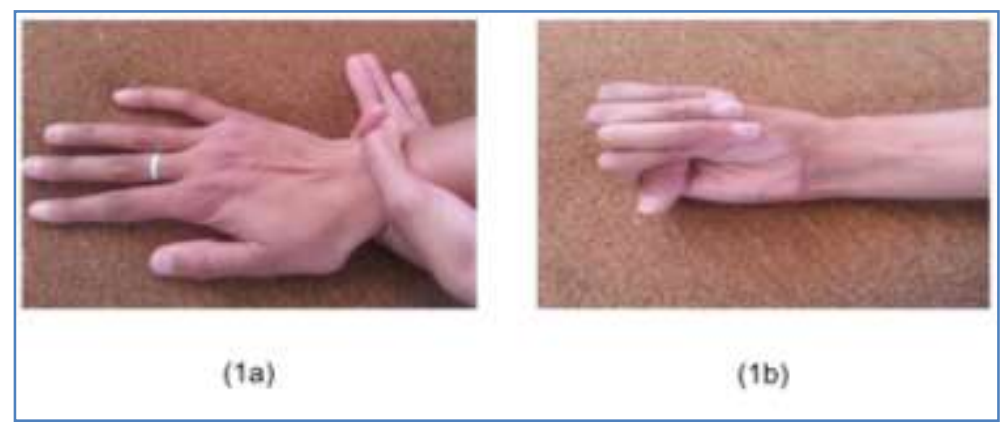

Fig-2: Arachnodactyly; 1a: signe de wrist; 1b: signe du thumb 


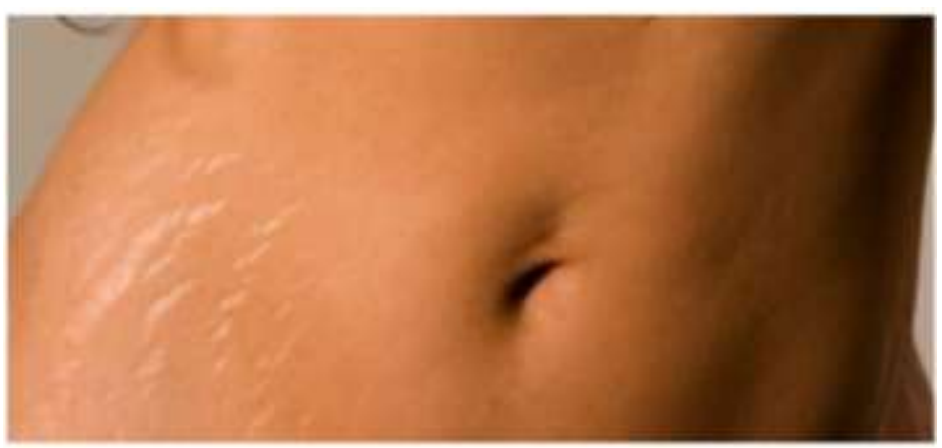

Fig-3: Stretch marks in the abdomen area

Table-1: System Score

\begin{tabular}{|l|c|}
\hline clinical signs & \\
\hline Thumb sign: the thumb protrudes from the closed fist, once the fingers closed on itself & 1 \\
\hline Wrist sign: a hand surrounds the contralateral wrist, positive if thumb and little finger cross & 3 \\
\hline Thumb sign and Wrist sign & 2 \\
\hline Pectus carinatum: sternum pushed forward & 1 \\
\hline Pectus excavatum: sternum pushed back & 2 \\
\hline Deviation of the hindfoot in valgus from the axis of the leg & 1 \\
\hline Flat feet & 1 \\
\hline Protrusion acétabulaire & 2 \\
\hline $\begin{array}{l}\text { Upper segment / lower segment ratio } \\
\text { decreases }\end{array}$ & 1 \\
\hline Scoliosis or thoracic kyphosis & 1 \\
\hline Limited elbow extension & 1 \\
\hline $\begin{array}{l}\text { Minimum 3 signs of the facies among the 5 following: dolichocephaly, enophthalmos, } \\
\text { inclination downwards of the palpebral slits, hypoplasia of the maxillary, retrognathia }\end{array}$ & \\
\hline Stretch marks & \\
\hline Dural ectasia & 1 \\
\hline Mitral valve prolapse & 2 \\
\hline Myopia greater than 3 diopters & 1 \\
\hline Spontaneous pneumothorax & \\
\hline
\end{tabular}

\section{REFERENCES}

1. Vigneron, A. M., \& Lioté, F. (2019). Le syndrome de Marfan. Revue du Rhumatisme Monographies, 86(2), 113-119.

2. Boileau, C., Jondeau, G., Mizuguchi, T., \& Matsumoto, N. (2005). Molecular genetics of Marfan syndrome. Current opinion in cardiology, 20(3), 194-200.

3. Dean, J. C. (2007). Marfan syndrome: clinical diagnosis and management. European Journal of Human Genetics, 15(7), 724-733.

4. Vanem, T. T., Geiran, O. R., Krohg- Sørensen, K., Røe, C., Paus, B., \& Rand- Hendriksen, S. (2018). Survival, causes of death, and cardiovascular events in patients with Marfan syndrome. Molecular genetics \& genomic medicine, 6(6), 1114-1123.
5. Loeys, B. L., Dietz, H. C., Braverman, A. C., Callewaert, B. L., De Backer, J., Devereux, R. B., \& Pyeritz, R. E. (2010). The revised Ghent nosology for the Marfan syndrome. Journal of medical genetics, 47(7), 476-485.

6. Jondeau, G., Barthelet, M., Van Kien, P. K. Lacombe, D., \& LA Douceur, M. (2006). Recommandations sur la prise en charge médicamenteuse des atteintes aortiques du syndrome de Marfan. Archive des maladies du coeur et des vaisseaux, 99(5), 540-546.

7. Gaudino, M., Girardi, L. N., Rahouma, M., Leonard, J. R., Di Franco, A., Lau, C., \& Demetres, M. (2018). Editor's Choice-Aortic Re-operation After Replacement of the Proximal Aorta: A Systematic Review and Meta-Analysis. European Journal of Vascular and Endovascular Surgery, 56(4), 515-523. 